\title{
RESEÑA
}

\section{World Conference on Fraternalism, Freemasonry \& History: Research in Ritual, Secrecy and Civil Society (Bibliothèque Nationale de France, París, 2017)}

\author{
Julio Martínez García \\ Universidad de Salamanca, España \\ juliomartinez.historiador@gmail.com
}

Recepción: 20 de octubre de 2017/Aceptación: 18 de noviembre de 2017

doi: https://doi.org/10.15517/rehmlac.v9i2.31387

\section{Introducción}

En estas últimas décadas se ha ido consolidando una visión más crítica y serena (sobre la historia de la masonería) en la mayor parte de los estudiosos e investigadores de todas las tendencias, gracias al avance de la interdisciplinariedad $\mathrm{y}$ al recurso a fuentes primarias documentales y hemerográficas hasta hace unos años desconocidas o poco utilizadas ${ }^{1}$.

De esta forma se expresaba en 2012 el profesor José Antonio Ferrer Benimeli al hablar de los avances que han existido en torno a las investigaciones históricas sobre las logias. A día de hoy existen expertos que intentan superar las enconadas perspectivas pro masónicas y anti masónicas, tan habituales durante el siglo XIX. Actualmente se busca realizar un análisis completo del fenómeno, en el que se aborden todas las aristas del mismo. Precisamente, éste fue el objetivo de la segunda edición de la World Conference on Fraternalism, Freemasonry \& History: Research in Ritual, Secrecy and Civil Society. "Se buscaba promover el dialogo entre estudiosos/as del tema de diferentes partes del mundo", señalaba -en declaraciones a REHMLAC+- Guillermo de los Reyes, uno de los impulsores de la cita $^{2}$. "Asimismo, también se pretendía la diseminación e intercambio de información en lo que se refiere a estudios de la masonería, fraternalismo y sociedad civil"3, añadía.

\footnotetext{
1 José Antonio Ferrer Benimeli, “Aproximación a la historiografía de la masonería latinoamericana", $\begin{array}{llllll}R E H M L A C & 4, & \text { no. } & 1 & \text { (mayo-noviembre } & 2012):\end{array}$ https://revistas.ucr.ac.cr/index.php/rehmlac/article/view/12144/11419

${ }^{2}$ Entrevista realizada al investigador Guillermo de los Reyes Heredia el 27 de octubre de 2017.

${ }^{3}$ Entrevista realizada al investigador Guillermo de los Reyes Heredia el 27 de octubre de 2017.
} 
La iniciativa tuvo lugar en la Biblioteca Nacional de Francia (BnF) -ubicada en París-, los días 26 y 27 de mayo de 2017. La dirección y organización del encuentro corrió a cargo de la Policy Studies Organization, que recibió la colaboración de la BnF y del Museo de la Francmasonería. Pero, ¿por qué se eligió la capital gala para la realización de este evento? Debido a "la gran cantidad de estudiosos/as de la masonería y al apoyo que nos dio la $\mathrm{BnF}^{\prime 4}$. En el encuentro participaron unos 80 investigadores, que dieron a conocer sus últimos trabajos, sometiéndolos al debate y reflexión de todos los presentes.

Precisamente, la divulgación de estas publicaciones es muy importante. Sobre todo en aquellas disciplinas que, tradicionalmente, no han tenido un hueco en los grandes discursos historiográficos ${ }^{5}$. Sólo con la generación de nuevos conocimientos $-\mathrm{y}$ su posterior difusión- se pueden dar a conocer los avances que se están desarrollando en este ámbito. El experto Esteban Rodríguez-Dobles lo tiene muy claro:

[...] la organización de un simposio o actividad similar sobre historia de la masonería exige dar pasos muy firmes. Con facilidad las personas, incluso los colegas historiadores, pueden desvirtuar la actividad académica, malentendiéndose o calificándola de convención masónica. Y [así] convertir en otra cosa lo que en realidad busca ser un espacio académico que proporciona herramientas interpretativas ante el fenómeno del asociacionismo moderno $[\ldots]^{6}$

Por ello, se debe difundir la labor que, actualmente, se realiza desde la "masonología" científica. Esta reseña pretende relatar algunos de los estudios que diversos investigadores presentaron en París en mayo de 2017. "El trabajo de divulgación debe ser llevado con especial cuidado y, de ser necesario, pecar de reiterativo a la hora de señalar el posicionamiento de la actividad en cuestión", defiende Rodríguez-Dobles. "No podemos pasar por alto el halo de misterio que ha rodeado al tema. Es parte de las situaciones con las que tenemos que lidiar" ${ }^{8}$, incide.

\footnotetext{
${ }_{5}^{4}$ Entrevista realizada al investigador Guillermo de los Reyes Heredia el 27 de octubre de 2017.

5 "Durante algún tiempo una especie de muro de la vergüenza separó el historiador especializado de la masonería del de la llamada historia general. Para los historiadores universitarios, la masonería estaba rodeada de una especie de tabú [...]" (Ferrer Benimeli, "Métodos y experiencias en el estudio de la historia de la masonería española", REHMLAC 1, no. 2 (diciembre 2009-abril 2010): 47, https://revistas.ucr.ac.cr/index.php/rehmlac/article/view/6617/6306). Sin embargo, esta realidad ya está cambiando. El propio Ferrer lo reconoce (Ferrer Benimeli, "Métodos y experiencias", 47). Se ha comenzado a derribar ese muro de la vergüenza y los estudios sobre la fraternidad comienzan a tener su espacio en el ámbito académico y universitario. Solo hay que ver ejemplos como el de esta revista o el del Centro de Estudios Históricos de la Masonería Española (CEHME), radicado en la Universidad de Zaragoza.

${ }^{6}$ Esteban Rodríguez-Dobles, "Reseña del IV Simposio Internacional de Historia de la Masonería y los Movimientos Asociativos Latinoamericanos y Caribeños: Prácticas asociativas y Modernidad, siglos XVIIIXXI (San José, Universidad de Costa Rica, 2015)", REHMLAC+, 7, 2 (diciembre 2015-abril 2016): 297, https://revistas.ucr.ac.cr/index.php/rehmlac/article/view/22769/23164

${ }^{7}$ Rodríguez-Dobles, "Reseña del IV Simposio Internacional", 297.

${ }^{8}$ Rodríguez-Dobles, "Reseña del IV Simposio Internacional", 297.
} 
En cualquier caso, desde hace algunas décadas se vienen realizando investigaciones universitarias sobre las logias. Hecho que permite un mayor conocimiento de dicha sociabilidad. "Afortunadamente, en los últimos años el tema masónico ha ido llamando cada vez más la atención de historiadores dispuestos a trabajar este asunto con nuevos documentos, con crítica de fuentes, con rigor metodológico y, sobre todo, con objetividad", explicita la historiadora María Eugenia Vázquez Semadeni. "Los trabajos recientes presentan propuestas de análisis novedosas, que permiten observar a la masonería en su interacción con los más diversos de la vida pública, desde la política hasta la educación"10, añade. Una perspectiva que comparte Ricardo Martínez Esquivel, cuando señala que esta sociabilidad, como objeto de estudio histórico, "ha experimentado un proceso sistemático de modernización en sus formas de análisis e interpretación"11.

Entre los aportes más sobresalientes de este grupo de historiadores [...] están: (i) la aplicación de la ciencia histórica en el análisis de la masonería; (ii) el uso de fuentes primarias masónicas y su cruce con otras como oficiales, eclesiales, lapidarias o de prensa; (iii) la creación de redes de investigadores y centros de investigación; (iv) la organización de congresos, simposios y coloquios especializados; y (v) la publicación de monografías y obras conjuntas ${ }^{12}$.

Unos postulados que han respetado todos y cada uno de los intervinientes en la World Conference on Fraternalism, Freemasonry \& History: Research in Ritual, Secrecy and Civil Society. De hecho, el texto que aquí comienza pretende ser un retrato resumido de lo que allí se debatió, ofreciendo un balance general del evento académico. Para ello, se señalarán algunas de las cuestiones que se abordaron durante la cita, que congregó a decenas de expertos sobre la mencionada disciplina. Como señala Fernando Anaya, "sirvan las presentes líneas para reflejar, con la brevedad requerida, cómo se desarrolló esta interesante reunión científica" ${ }^{\prime 3}$.

\footnotetext{
9 María Eugenia Vázquez Semadeni, "Historiografía sobre la masonería en México. Breve revisión", $\begin{array}{llllll}R E H M L A C & 2, & \text { no. } & 1 & \text { (mayo-noviembre } & 2010 \text { ): }\end{array}$ https://revistas.ucr.ac.cr/index.php/rehmlac/article/view/6608/6297

${ }^{10}$ Vázquez Semadeni, "Historiografía sobre la masonería", 28.

${ }^{11}$ Ricardo Martínez Esquivel, "Prosopografía y redes sociales: notas metodológicas sobre el estudio de la masonería en Costa Rica", REHMLAC+ 7, no. 2 (diciembre 2015-abril 2016): 1, https://revistas.ucr.ac.cr/index.php/rehmlac/article/view/22689/23150

12 Martínez Esquivel, "Hacia la construcción de una historia social de la masonería en Centroamérica", Revista Estudios 27 (2013): 203, https://revistas.ucr.ac.cr/index.php/estudios/article/view/12703/11951

13 Fernando Anaya Gámez, "Reseña del Congreso Internacional SocyHume: «De la Sociabilidad al Patrimonio Histórico y Cultural» (Centro Interdisciplinar de História, Culturas e Sociedades, Universidad de Évora, Portugal, 2016)", REHMLAC+ 8, no. 2 (diciembre 2016-abril 2017): 297, https://revistas.ucr.ac.cr/index.php/rehmlac/article/view/26781/27366
} 


\section{El discurrir de la Conferencia}

Por tanto, la presente reseña no busca la pretenciosidad. Simplemente, desea hacer un pequeño repaso del mencionado congreso. Una cita en la que participaron unos 80 investigadores. Por tanto, los asuntos tratados fueron muy amplios. Guillermo de los Reyes destaca alguno de ellos, como el análisis de "la figura de Ramsay; los 300 años de la masonería y el debate de los orígenes; la masonería como sociedad internacional; regularidad e irregularidad; Compagnonnage..."14. También hubo mesas centradas en la idea de sociabilidad y sociedad civil; en logias y música; arquitectura; artes visuales; o sobre género, entre otros muchos asuntos. E, incluso, se programó una temática denominada «Imperialism, Colonialism and Multiple Freemasonries» que, dividida en varias sesiones, tuvo una muy buena acogida.

Asimismo, también se planificaron otras actividades paralelas, como un seminario centrado en la figura de Andrew Michael Ramsay, que se desarrolló en el Museo de la Francmasonería. Esta propuesta se centró en la influencia masónica que tuvo el mencionado personaje. Para ello, se analizaron diversos documentos. La cita tuvo lugar el miércoles, 24 de mayo, dos días antes del inicio oficial de la World Conference on Fraternalism, Freemasonry \& History: Research in Ritual.

Además, "durante las dos jornadas de la Conferencia también hubo una profundización en diferentes aspectos de la figura de Ramsay"15. Entre los expertos que trataron dicha figura se encontraron Pierre Mollier, Francis Delon, Pierre Besses, Louis Trebuchet, Arnaud Marquet, Reinhard Markner, Sophie Desplanches, Andreas Önnerfors, Aymeric Le Delliou, Samuel Macaigne o Karen Kidd, quien habló de la mujer masona en tiempos de Ramsay. Por tanto, el análisis del mencionado personaje fue muy importante y diverso.

Una variedad temática que caracterizó la totalidad de la Conferencia. Esta multidisciplinariedad, además, se vio acompañada de la gran calidad de todos los ponentes. Entre los investigadores participantes se encontraron Paul Rich, presidente de la Policy Studies Organization y autor de varios libros y artículos sobre la masonería en el Golfo Pérsico y en América Latina; Margaret Jacob, catedrática en el Departamento de Historia en la Universidad de California en Los Angeles, fundadora del «Centro de Estudios de Masonería y Sociedad Civil» en la UCLA y autora de Living the Enlightenment: Freemasonry and Politics in Eighteenth-Century Europe; y Pierre Mollier, director del Museo de la Francmasonería y editor de la revista Ritual, Secrecy, and Civil Society.

\footnotetext{
${ }^{14}$ Entrevista realizada al investigador Guillermo de los Reyes Heredia el 27 de octubre de 2017.

${ }^{15}$ François Moray, "Le monde de la recherche maçonnique se retrouve à Paris“, Franc-maçonnerie Magazine (julio-agosto 2017) : 9.
} 
Asimismo, durante el evento parisino intervinieron otros investigadores de primer nivel, como María Eugenia Vázquez Semadeni. "El trabajo que presenté versó sobre la forma en que la masonería contribuyó a la formación del Estado mexicano durante el siglo XIX y la primera mitad del siglo XX. En particular, en torno a cómo impulsó la formación de la cultura política republicana y la manera en que sustituyó a los partidos políticos", explica en una conversación mantenida con REHMLAC+ ${ }^{16}$. Para realizar este análisis empleó una metodología basada en "una combinación de historia de la prensa, historia de la institución masónica, historia política y social, e historia cultural. Principalmente siguiendo los planteamientos de Joseph and Nugent en Everyday Forms of State Formation", explica la investigadora ${ }^{17}$.

"Siguiendo los lineamientos de los profesores Ferrer Benimeli y Jacob, he desarrollado una tendencia [historiográfica] a la que denomino «Masonería en su contexto»"18, explica Vázquez Semadeni. Esta formulación "implica estudiar esta realidad no sólo desde la regularidad, sino incluyendo todo lo que en su momento fue considerado masonería, ya fuera por los propios masones o por sus detractores" ${ }^{" 19}$, concluye la experta mexicana.

Otro de los ponentes fue Yván Pozuelo Andrés, del IES Universidad Laboral de Gijón. La intervención, denominada «Impérialismes, maçonniques et... politiques», destacó por su espléndida capacidad comunicativa. "Traté de abordar el rol de la masonería en las conquistas imperialistas de los últimos tres siglos", indica Pozuelo en declaraciones a REHMLAC $+{ }^{20}$. "Fue un planteamiento general sobre la temática, con el fin de animar a los investigadores a adentrarse en ella" ${ }^{21}$ explica. "Aún está poco atendida. Sin embargo, su importancia es crucial para entender la extensión y la permanencia de la masonería como asociación tres siglos después de su puesta en marcha",22, añade.

En su trabajo, el investigador asturiano empleó una perspectiva "total". "Utilicé todo tipo de documentación al servicio del conocimiento histórico. En mi caso podría resumirla como «escuela del CEHME»" ${ }^{23}$, añade. Un posicionamiento que es compartido por Dévrig Mollès. "La cuestión masónica remite a una historia global. De una forma u otra, atraviesa la totalidad del mundo moderno" ${ }^{, 24}$.

\footnotetext{
${ }^{16}$ Entrevista realizada a la investigadora María Eugenia Vázquez Semadeni el 27 de octubre de 2017.

${ }^{17}$ Entrevista realizada a la investigadora María Eugenia Vázquez Semadeni el 27 de octubre de 2017.

${ }^{18}$ Entrevista realizada a la investigadora María Eugenia Vázquez Semadeni el 27 de octubre de 2017.

${ }^{19}$ Entrevista realizada a la investigadora María Eugenia Vázquez Semadeni el 27 de octubre de 2017.

${ }^{20}$ Entrevista realizada al investigador Yván Pozuelo el 27 de octubre de 2017.

${ }^{21}$ Entrevista realizada al investigador Yván Pozuelo el 27 de octubre de 2017.

${ }^{22}$ Entrevista realizada al investigador Yván Pozuelo el 27 de octubre de 2017.

${ }^{23}$ Entrevista realizada al investigador Yván Pozuelo el 27 de octubre de 2017.

${ }^{24}$ Dévrig Mollès, "L'histoire globale et la question maçonnique: éléments pour une analyse“, REHMLAC 6, no. 1 (mayo-diciembre 2014), 6, https://revistas.ucr.ac.cr/index.php/rehmlac/article/view/15225/14524
} 
En este mismo sentido, autores como Rogelio Aragón, de la Universidad Iberoamericana de México, y Felipe Côrte Real de Camargo, adscrito a la Universidad de Bristol, también quisieron centrarse en «Imperialismo, colonialismo y múltiples masonerías». El primero de ellos -Rogelio Aragón- habló sobre el «Imperialismo fraterno: la pugna entre el GOF y la UGLE», mientras que Felipe Côrte Real de Camargo analizó el siguiente tema: «Dependencia y autonomía: masones ingleses y sus relaciones en Argentina y Brasil (1859-1935)».

En la Conferencia de París también intervino la investigadora Sylvia Hottinger, con un trabajo llamado «El imperio contra el pueblo: ¿Presencia masónica en la Semana Trágica de Barcelona (1909)?». "La tendencia historiográfica que utilicé fue la de la historia cultural, principalmente sus enlaces recientes con los estudios de comunicación con los culturales" 25 , explica la doctora. "Esta mezcla busca una lectura de las imágenes más allá de los formalismos estéticos. Y, por tanto, más cerca de una interpretación cultural y política descontextualizada de la prensa en que fue presentada a la sociedad de la época", añade $^{26}$. Para poder desarrollar este trabajo, Hottinger manejó un procedimiento muy preciso. "La metodología fue la lectura de imágenes, no relacionado a una semiótica, pero sí a una investigación del contexto de producción de las fotos"27.

Por otro lado, la investigadora de la Universidad Jaume I de Castellón, Valeria Aguiar, tituló su participación en la Conferencia de París bajo el nombre: «Hermano moro, masonería y colonialismo en el Protectorado Español de Marruecos (1931-1936)». "Mi presentación versó sobre el proyecto colonialista y cosmopolitista de la masonería española en el protectorado marroquí", narra Aguiar a REHMLAC+ ${ }^{28}$. "En concreto, me centré en la vinculación entre este proyecto ideal del colonialismo masónico, la imagen heredada de los marroquíes por los españoles y los preceptos masónicos respecto a la otredad religiosa, para determinar quién o quiénes podían iniciarse en la orden, y cuáles fueron las causas de ello"29, puntualiza. "Además, en sentido inverso, intenté aproximarme a las variables conceptuales, culturales y contextuales de los propios marroquíes que se iniciaron en la masonería" ${ }^{30}$, añade.

Una labor que recibió muy buenas críticas. "Como es un trabajo sobre la alteridad y las representaciones de la diferencia dentro de un contexto colonial y masónico, la tendencia historiográfica que utilicé fue la sociología del imaginario de tradición francesa, así como la teoría foucaultiana de la construcción de discursos"31 , explica. "La metodología que empleé fue el análisis riguroso de los discursos producidos por las logias españolas en

\footnotetext{
${ }^{25}$ Entrevista realizada a la investigadora Sylvia Hottinger el 27 de octubre de 2017.

${ }^{26}$ Entrevista realizada a la investigadora Sylvia Hottinger el 27 de octubre de 2017.

${ }^{27}$ Entrevista realizada a la investigadora Sylvia Hottinger el 27 de octubre de 2017.

${ }^{28}$ Entrevista realizada a la investigadora Valeria Aguiar el 27 de octubre de 2017.

${ }^{29}$ Entrevista realizada a la investigadora Valeria Aguiar el 27 de octubre de 2017.

${ }^{30}$ Entrevista realizada a la investigadora Valeria Aguiar el 27 de octubre de 2017.

${ }^{31}$ Entrevista realizada a la investigadora Valeria Aguiar el 27 de octubre de 2017.
} 
el Magreb, además de su contraste con diversa bibliografía sobre la sociología del imaginario, la alteridad en la historia de España, las representaciones, el nacionalismo marroquí y la masonería colonial española y francesa ${ }^{\text {"32 }}$, describe Aguiar.

Pero, más allá de estas intervenciones y del análisis a la figura de Ramsay, también hubo espacio para otras temáticas. Por ejemplo, la conmemoración del $300^{\circ}$ aniversario de la masonería especulativa, que se cumple en 2017. De hecho, se organizó un panel centrado en los orígenes de la mencionada sociabilidad. En la mesa intervinieron expertos de reconocido prestigio, como Louis Trebuchet, que habló de la influencia del conflicto entre Whigs y Estuardos en las Grandes Logias de Londres y de Francia; o Michel Warnery, que examinó los talleres alemanes a inicios del siglo XVIII.

Otros asuntos que generaron mucho interés fueron aquellos relacionados con el arte, la arquitectura y la música. Por ejemplo India D’Avignon habló de «Freemasons Franklin, Mozart, Mesmer and the Glass Armonica». Por otro lado, David Martín López, Alisa Luxenberg y Talinn Grigor participaron de la temática «Freemasonry and the Exploration of Architecture». Asimismo, hubo un panel que recibió el nombre de «Transformations in the Art of Freemasonry in the U.S. from the Late Eighteenth Century», en el que hablaron investigadores de primer nivel. Incluso hubo un estudio centrado en la representación de la fraternidad en la industria cultural contemporánea. Lo realizó Julio Martínez, que se centró en los ejemplos de Dan Brown y de Los Simpsons.

En otro orden de cosas, también hubo varias mesas centradas en el enfoque de género, que recibieron el nombre de «Women and Freemasonry in Europe and the United States» o «Ramsay and Women». En los mencionados paneles participaron expertas de reconocido prestigio, como Natalie Bayer, Olivia Chaumont, Marie-Anne Mersch, Celia Poulet, Cécile Révauger, Karen Kidd o el historiador Yves Hivert-Messeca, entre otros. Todas ellas y él se aproximaron a la masonería femenina, abordando diferentes temas relacionados con dicha cuestión y tratándolos desde una perspectiva académica y analítica. Cada una de sus intervenciones suscitó un gran interés entre los asistentes, generando un enriquecedor debate posterior.

En consecuencia, y como se ha podido observar, el estudio de las logias se puede abordar desde una gran variedad de perspectivas. Un planteamiento diverso que se observó muy claramente en la Conferencia de París de mayo de 2017 y que defienden muchos investigadores. Entre ellos, José Antonio Ferrer Benimeli:

El tema [de la sociabilidad masónica] está abierto a múltiples enfoques y disciplinas, ya que la masonería se puede estudiar no sólo desde la historia, sino también desde la literatura, el arte y la música, la arquitectura, la filosofía, la educación, la sociología, la prensa, el feminismo, el colonialismo, el nacionalismo, la democracia, la independencia de los pueblos, el republicanismo, el pacifismo, las

\footnotetext{
${ }^{32}$ Entrevista realizada a la investigadora Valeria Aguiar el 27 de octubre de 2017.
} 
biografías... y hasta desde la jardinería, a través de su presencia en los llamados jardines iniciáticos y románticos ${ }^{33}$.

\section{Conclusión}

Por tanto, la World Conference on Fraternalism, Freemasonry \& History: Research in Ritual, Secrecy and Civil Society, desarrollada en mayo de 2017 en la BnF, se definió por la pluralidad de trabajos y perspectivas, así como por los debates que se desarrollaron en su seno. Precisamente, desde la organización del evento ponen en valor estos elementos. "Destacamos el carácter interdisciplinario de los temas presentados, la variedad de los mismos y su calidad" ${ }^{34}$, explica Guillermo de los Reyes. "Nos gustó la discusión informada entre expertos de la masonería que no pertenecen a ella y aquellos miembros de la organización que también la estudian de manera seria"35, asegura. "Es importante que haya un diálogo entre los interesados en dichos temas para que se analicen las fuentes y se hable sobre los archivos que contienen materiales sobre la masonería $[\ldots]^{336}$, concluye el profesor de la Universidad de Houston.

En definitiva, se trató de una cita académica de primer nivel, en la que se reflexionó en torno a diferentes asuntos relativos a la mencionada sociabilidad:

Afortunadamente, la masonería ha empezado a interesar a los universitarios desde una óptica más científica y desmitificadora, y menos apasionada, por no decir obsesiva y patológica de ciertas escuelas historiográficas necesitadas de falsos maniqueísmos donde enfrentar a supuestos buenos y malos. La masonería ha entrado finalmente en la universidad, entre otras cosas, porque ahora se investiga más y mejor; porque los tópicos fáciles y manidos no sirven ya; porque el universitario quiere saber y busca esa verdad hasta ahora encubierta, en no pocos casos, por intereses ajenos a la ciencia; porque cada generación tiene el deber de hacer su propia historia sometiendo a revisión la que le han legado sus mayores, sobre todo cuando ésta ha sido marcada por la polémica y el fanatismo ideológico, político o religioso ${ }^{37}$.

Las próximas citas de la World Conference on Fraternalism tendrán lugar tanto en París -en 2019 y 2021- como en Washington, en 2018 y 2020. En el caso de la capital francesa se reeditará la sede de la $\mathrm{BnF}$, mientras que en la ciudad estadounidense se

\footnotetext{
${ }^{33}$ Ferrer Benimeli, "Métodos y experiencias", 47.

${ }^{34}$ Entrevista realizada al investigador Guillermo de los Reyes Heredia el 27 de octubre de 2017.

${ }^{35}$ Entrevista realizada al investigador Guillermo de los Reyes Heredia el 27 de octubre de 2017.

${ }^{36}$ Guillermo de los Reyes Heredia, "Los estudios masónicos estadounidense y su impacto en la masonería latinoamericana. Una aproximación historiográfica", REHMLAC 4, no. 1 (mayo-noviembre 2012): 153, https://revistas.ucr.ac.cr/index.php/rehmlac/article/view/12146/11421

${ }^{37}$ Ferrer Benimeli, "Métodos y experiencias", 47.
} 
desarrollará en la Whittemore House. Según señalan los organizadores, el tema principal de la Conferencia de 2018 será la participación de la mujer en este tipo de sociedades, mientras que el de 2019 se centrará en el origen y la creación de los grados y los ritos. Una circunstancia que no excluye el tratamiento de otros asuntos.

\section{Bibliografía}

Anaya Gámez, Fernando. "Reseña del Congreso Internacional SocyHume: «De la Sociabilidad al Patrimonio Histórico y Cultural» (Centro Interdisciplinar de História, Culturas e Sociedades, Universidad de Évora, Portugal, 2016)". REHMLAC+ 8, no. 2 (diciembre 2016-abril 2017): 297-306. https://revistas.ucr.ac.cr/index.php/rehmlac/article/view/26781/27366

Ferrer Benimeli, José Antonio. "Aproximación a la historiografía de la masonería latinoamericana". REHMLAC 4, no. 1 (mayo 2012-noviembre 2012), 1-121. https://revistas.ucr.ac.cr/index.php/rehmlac/article/view/12144/11419

Ferrer Benimeli, José Antonio. "Métodos y experiencias en el estudio de la historia de la masonería española". REHMLAC 1, no. 2 (diciembre 2009-abril 2010), 46-62. https://revistas.ucr.ac.cr/index.php/rehmlac/article/view/6617/6306

Martínez Esquivel, Ricardo. "Hacia la construcción de una historia social de la Masonería en Centroamérica". Revista Estudios 27 (2013): 201-247. https://revistas.ucr.ac.cr/index.php/estudios/article/view/12703/11951

Martínez Esquivel, Ricardo. "Prosopografía y redes sociales: notas metodológicas sobre el estudio de la masonería en Costa Rica". REHMLAC+ 7, no. 2 (diciembre 2015-abril 2016): 1-27. https://revistas.ucr.ac.cr/index.php/rehmlac/article/view/22689/23150

Mollès, Dévrig, "L'histoire globale et la question maçonnique: éléments pour une analyse", REHMLAC+, 6, 1 (mayo 2014-diciembre 2014), 1-32.

Moray, François. "Le monde de la recherche maçonnique se retrouve à Paris ». Francmaçonnerie Magazine (julio-agosto 2017).

Reyes Heredia, Guillermo de los. "Los estudios masónicos estadounidense y su impacto en la masonería latinoamericana. Una aproximación historiográfica". REHMLAC 4, no. 1 (mayo-noviembre 2012): 141-157. https://revistas.ucr.ac.cr/index.php/rehmlac/article/view/12146/11421

Rodríguez-Dobles, Esteban. "Reseña del IV Simposio Internacional de Historia de la Masonería y los Movimientos Asociativos Latinoamericanos y Caribeños: Prácticas asociativas y Modernidad, siglos XVIII-XXI (San José, Universidad de Costa Rica, 2015)". REHMLAC+ 7, no. 2 (diciembre 2015-abril 2016): 297-317. https://revistas.ucr.ac.cr/index.php/rehmlac/article/view/22769/23164 
Vázquez Semadeni, María Eugenia. "Historiografía sobre la masonería en México. Breve revisión". REHMLAC 2, no. 1 (mayo-noviembre 2010): 16-29. https://revistas.ucr.ac.cr/index.php/rehmlac/article/view/6608/6297

\section{Otros Recursos}

Entrevista realizada al investigador Guillermo de los Reyes Heredia el 27 de octubre de 2017.

Entrevista realizada a la investigadora María Eugenia Vázquez Semadeni el 27 de octubre de 2017.

Entrevista realizada a la investigadora Sylvia Hottinger el 27 de octubre de 2017.

Entrevista realizada a la investigadora Valeria Aguiar el 27 de octubre de 2017.

Entrevista realizada al investigador Yván Pozuelo Andrés el 27 de octubre de 2017.

\section{Anexo \\ Programa de la Conferencia}

\section{Friday May 26}

9:30-11:00. Plenary.

Co-Chairs: "The Idea of Associating: Fraternalism and Civil Society», Margaret Jacob, Naomi Taback, Natalie Bayer, María Eugenia Vázquez Semadeni.

11:00-11:20. Presentation of Bartholdi Award for Distinguished Scholarship.

11:20-13:00. «Eighteenth Century Origins and Consequences», Pierre Mollier, Chair.

«Influence du conflit entre Whigs et Stuards sur la création de la Grande Loge de Londres et de la Grand Loge de France», Louis Trebuchet.

«Les Lumières et la Franc-maçonnerie allemande au début de 18ème siècle et plus tard», Michel Warnery.

«Lire les images de la Franc-maçonnerie: l'exemple des 'Gabanons' (1745)», Philippe Langlet.

«New Historical Perspectives: the higher degrees of the 'French Rite», Cécile Révauger, Université Bordeaux Montaigne. 
13:00-14:00. Movie Excerpts from «The Man Who Would Be King», Guillermo Izabal, Chair.

14:00-15:30. "The Various Versions of Ramsay's Discourse». Presentation by Alain Bernheim. Pierre Mollier, Chair.

15:30-15:50. Presentation of the Regulus Award by Pierre Mollier.

15:50-17:30. «Restoring the Compagnonnage to Fraternal History: Further Considerations», Margaret Jacob, Chair.

«The Stone and the Compass: The Company of the Humanity of the Stonemasons of Tours: Cross Paths between Compagnonnage, Mutualism, and Freemasonry», Jean MichelMathonière, Centre d'étude des compagnonnages à Avignon.

11:30-12:00. «Music and Masonry», Naomi Taback, Chair.

«Freemasons Franklin, Mozart, Mesmer and the Glass Armonica», India D'Avignon, California Polytechnic State University.

14:00-18:00. «Freemasonry and Visual Arts: A Symposium», Reva Wolf, State University of New York at New Paltz; and Alisa Luxenberg, University of Georgia, Athens, Chairs.

\section{4:00-15:15. Part 1: Freemasonry and the Exploration of Architecture.}

«Freemasonry in Eighteenth-Century Portugal and the Architectural Projects of the Marquis de Pombal», David Martín López, University of Granada.

«Building Codes: New Light on Baron Taylor and Les Voyages pittoresques et romantiques dans l'ancienne France», Alisa Luxenberg, University of Georgia.

«Reveil de l'Iran: Freemasonry and Artistic Revivalism from Parsi Bombay to Qajar Tehran», Talinn Grigor, University of California, Davis.

15:30-16:45. Part 2: Art, Freemasonry, and Social and Political Upheaval.

«Meissen Porcelain and the Order of the Pug», Cordula Bischoff, independent scholar. «Goya's Art and Freemasonry in Spain», Reva Wolf, State University of New York at New Paltz.

«Masonic Imagery in Haitian Vodou», Katherine Marie Smith, New York University. 
16:45-18:00. Part 3: Transformations in the Art of Freemasonry in the U.S. from the Late Eighteenth Century to the 1960s.

«Within the Compass of Good Citizens': The Visual Arts of Freemasonry as Practiced by Paul Revere», Nan Wolverton, American Antiquarian Society.

«To Consummate the Plan: Solomon's Temple in Masonic Art, Architecture and Popular Culture, 1865-1930», William D. Moore, Boston University.

«A Change Is Gonna Come': Imaging Black Freemasons from Emancipation to the 1960s», Cheryl Finley, Cornell University, and Deborah Willis, New York University.

11:00-12:00. «Three International Perspectives», Guillermo Izabal, Chair.

«Freemasonry and Natural Sciences in Late Eighteenth Century- Example of Georg Vega», Matevž Košir, Archives of the Republic of Slovenia.

«A Curious Swiss Certificate of 1779», Michel Jaccard, former president of the ARGO.

«The Practice of Freemasonry in the Islamic World Through the Most Ancient Masonic

Ritual in Arabic», Saïd Chaaya, UCLA, Department of History.

14:00-15:30. «Intellectual Antecedents, Foundations, and Linkages», María Eugenia Vázquez Semadeni, Chair.

«German Masonry, Monarchy, Protestantism: Linkages from the Napoleonic Wars to the Overthrow of the Crowns (1918)», Ralf Bern Herden.

«Jean-Baptiste Willermoz: Intellectual Failure or Masonic Mastermind», Aaron Jedediah French, University of California, Davis.

«Creating a Foundation for Fraternalism in America: Literary and Debating Societies in the US Colonial Colleges», Wayne Kraemer and Ann Burnette.

15:30-15:50. Presentation of Kilwinning Award.

15:50-17:30. «Contemporary Scholarship views Fraternalism», Natalie Bayer, Chair.

«The Fraternal Order of Elks: U.S. Drinking and Driving Laws' Impact on Elk Lodge Life: Exalted Rulers' Perceptions», John C. Mero, Campbell University.

«Contemporary Freemasonry: A Sociological Model of Member Involvement», J. Scott Kenney.

«Invisible Truth: Modeling Secularity through Language and Performance Games in Masonic Rituals», Klaus-Jürgen Grün. 
«El tratamiento iconográfico de la Masonería. El caso de las series televisivas y la literatura», Julio Martínez García, Universidad de Salamanca.

17:30-18:00. "Regularity, Recognition and Painting Ourselves into the Corner Again: A Plenary Workshop Discussion», Mike Kearsley, Gilbert Davau, John Belton, Chairs.

\section{Saturday May 27}

9:30-10:45. Plenary.

«James Anderson and the Myth of 1717», Susan Sommers, Professor of History, Saint Vincent College. Mike Kearsley, Chair

11:00 -13:00. «Aspects in Dispute: Past and Present of the French Masonic Scene», Alain Bauer and Roger Dachez, Co-chairs.

«Cartoons, Thrillers, and Freemasonry», Alain Bauer, Alain Jacques Lacot (TBC), Didier Convard (TBC), Eric Giacometti (TBC), Jacques Ravenne (TBC).

«Lire les images de la franc-maçonnerie: l'exemple des 'Gabanons' (1745)», Philippe Langlet.

13:00-14:00. Movie Excerpts. Guillermo Izabal, Chair.

14:00-16:00. Imperialism, Colonialism and Multiple Freemasonries. Part 2. Guillermo De Los Reyes, Chair.

«El imperio contra el pueblo. ¿Presencia Masónica en la Semana Trágica de Barcelona (1909)?», Sylvia Hottinger, Independent Scholar, CEHME, REHMLAC+.

«Hermano moro, masonería y colonialismo en Protectorado Español de Marruecos (19311936)», Valeria Aguiar Bobet, Universidad Jaume I de Castellón.

«Impérialismes, maçonniques et... politiques», Yván Pozuelo Andrés, IES Universidad Laboral de Gijón, CEHME, REHMLAC+.

16:20-17:15. The «Ramsay Summation», Pierre Mollier, Cécile Révauger, Margaret Jacob, Alain Bernheim, Paul Rich, Guillermo De Los Reyes.

9:30-10:45. Imperialism, Colonialism and Multiple Freemasonries. Part 1. Guillermo De Los Reyes, Chair. 
«Dependence and Autonomy: The English Freemasons and their Relations in Argentina and Brazil (1859-1935)», Felipe Côrte Real de Camargo, University of Bristol.

«El discurso antimasónico católico en la defensa del imperio español. Entre antilumieres y contrarrevolución», Felipe Santiago del Solar, Independent Scholar.

«Imperialismo Fraterno: la pugna entre el GOF y la UGLE», Rogelio Aragón, Universidad Iberoamericana, Mexico City.

«The Revolutionary Morality of Freemasonry: Universal Justice and Solidarity since the Paris Commune», Alhelí de María Alvarado-Díaz.

11:05-13:00. «Ramsay and His Relationships to Intellectual History», Craig Remes, Chair.

«The Influence of the Scottish Poem 'The Bruce of John Harbour' (about 1375) on the Ramsay's Oration», Francis Delon.

«A Rereading of Ramsay's Oration 1737: The Dream of the Spiritual Empire in its Context of the New Catholic and Stuart Revival», Pierre Besses \& Louis Trebuchet.

«The Paternity of Ramsay's Speeches: de La Motta, Madame de Guyon, and the Corridors of Power», Arnaud Marquet.

«Anton von Geusau's Conversations with Ramsay: An Examination of his Original Diary», Reinhard Markner, University of Innsbruck.

«Ramsay et le Jacobitisme, évolution d'une relation durable», Sophie Desplanches.

14:00-16:00. «Ramsay and his Disputed Contributions», Andreas Önnerfors, Chair.

«L'entourage spirituel de Ramsay en France: du 'Pur Amour' de Fenelon et Mme Guyon à la 'Fraternité universelle'», Aymeric Le Delliou.

«Ramsay's ideas on World Citizenship and Cosmopolitanism», Andreas Önnerfors.

«Les Voyages de Cyrus' du Chevalier de Ramsay: entre roman spirituel et conte philosophique», Samuel Macaigne.

16:20-17:15. «Ramsay Summation», Pierre Mollier, Cécile Révauger, Margaret Jacob, Alain Bernheim, Paul Rich, Guillermo De Los Reyes.

9:30-10:30. «Italian Conundrums», Paul Rich, Chair.

«War or Peace: the Grand Orient of Italy and World War I», Demetrio Xoccato.

«Freemasonry in Libya», Emanuela Locci.

«Italian Freemasonry and the Free State of Fiume», Ljubinka Toševa Karpowicz, University of Ljubljana. 
10:30-11:00. Natalie Bayer, Chair

«The Sea Serjeants: A Jacobite Pseudo-Masonic Society in the Maritime Counties of South Wales in the First Half of the Eighteenth Century», Francis Delon.

11:20-13:00. «Women and Freemasonry in Europe and the United States», Natalie Bayer, Chair.

«The GOdF and Gender Issues at the Turn of the Twenty-First Century», Olivia Chaumont. «Women and Freemasonry in the 18th Century, a Comparative Study Between France, England, and Germany», Marie-Anne Mersch, Université Bordeaux Montaigne.

«Democracy and Expressing Oneself in Lodge: Similarities and Differences between Male and Female Lodges», Celia Poulet, Université Bordeaux Montaigne.

«Excluding/Including Women, an Issue for the Masonic Atlantic», Cécile Révauger, Université Bordeaux Montaigne.

14:00-14:45. «Ramsay and Women», Mike Kearsley, Chair.

«Women Operative Masons and Freemasons in the Time of Ramsay», Karen Kidd.

«Could the English Amazons be considered French Freemasons?», Yves Hivert-Messeca.

14:45-15:45. «The Cauldron of Masonic invention», Cécile Révauger, Université Bordeaux Montaigne, Chair.

«Degrés intermédiaires: additions au système des illuminés de Bavière récemment trouvées», Reinhard Markner, University of Innsbruck.

«The Scottish Rectified Rite: A French Masonic Exception», Roger Dachez.

«Historical Reconsiderations: Franz Joseph Haydn - The Man and the Mason, Mozart's Masonic Music», David H. Lewis, University College, London.

16:00-16:20. Presentation of Award for Lifetime Achievement.

16:20-17:15. «Ramsay Summation», Pierre Mollier, Cécile Révauger, Margaret Jacob, Alain Bernheim, Paul Rich. 